\title{
Effect of Pulse and Direct Current Electrodeposition on Microstructure, Surface, and Scratch Resistance Properties of Ni-W Alloy and Ni-W-SiC Composite Coatings
}

\author{
Sami Bin Humam ${ }^{1} \cdot$ Gobinda Gyawali $^{2}$ - Dhani Ram Dhakal ${ }^{1}$ Jin-Hyuk Choi ${ }^{1}$. Soo Wohn Lee ${ }^{1}$
}

Received: 10 April 2020 / Revised: 11 May 2020 / Accepted: 27 May 2020 / Published online: 7 July 2020

(C) The Chinese Society for Metals (CSM) and Springer-Verlag GmbH Germany, part of Springer Nature 2020

\begin{abstract}
The present work aims to study the influence of direct current and pulse current techniques as well as embedded SiC nanoparticles on the mechanical properties of the electrodeposited $\mathrm{Ni}-\mathrm{W}$ coating. The electrodeposited coatings were studied for morphological, microstructural, mechanical, and scratch resistance properties using the surface roughness tester, scanning electron microscopy, energy-dispersive X-ray spectroscopy, X-ray diffraction, Vickers microhardness, and scratch tester. Application of pulse current exhibited relatively homogeneous and smooth surface of the coatings. A remarkable increment of microhardness was observed in both $\mathrm{Ni}-\mathrm{W}$ and $\mathrm{Ni}-\mathrm{W}-\mathrm{SiC}$ coatings prepared under pulse current as compared to the direct current technique. Similarly, the scratch test revealed a considerable improvement in the scratch resistance behavior of the Ni-W alloy and the composite coatings from the pulsed current condition. Hence, the application of pulse current not only improved the surface- and microstructure-related properties but also enhanced the Vickers microhardness and scratch resistance properties of the coatings. In addition, the reduction in micro-cracks revealed the improvement in scratch resistance properties of the coatings due to the incorporated $\mathrm{SiC}$ nanoparticles into the $\mathrm{Ni}-\mathrm{W}$ alloy matrix.
\end{abstract}

Keywords $\mathrm{Ni}-\mathrm{W}-\mathrm{SiC}$ composite $\cdot$ Surface $\cdot$ Microstructure $\cdot$ Microhardness $\cdot$ Scratch resistance

\section{Introduction}

Electrodeposition of metal-based composites containing embedded inert particles has been extensively studied since Fink and Prince [1] first investigated the graphite codeposition into the $\mathrm{Cu}$ matrix. Metal matrix composites (MMCs) have received widespread attention among the scientific community due to their outstanding mechanical, tribological, electrical, thermal, and corrosion resistance properties [2] for the development of multifunctional composite coatings.

Available online at http://link.springer.com/journal/40195.

Gobinda Gyawali

ggobinda@sunmoon.ac.kr

Soo Wohn Lee

swlee@sunmoon.ac.kr

1 Department of Environmental and Bio-Chemical Engineering, Sun Moon University, Asan 31460, Korea

2 Department of Fusion Science and Technology, Sun Moon University, Asan 31460, Korea
Among commonly investigated of metal-matrix system, $\mathrm{Ni}-\mathrm{W}$ alloys are of considerable interest due to their unique characteristic features such as good chemical and thermal stability, high hardness, high wear resistance at elevated temperatures, high melting point, low coefficient of thermal expansion, high tensile strength, and high corrosion resistance in extreme conditions [3-5]. Although hard chrome ( $\mathrm{HCr}$ ) coating possesses excellent mechanical and electrochemical corrosion-resistant properties, the hazardous effects of chromium coatings due to the generation of carcinogenic hexavalent chromium $\left(\mathrm{Cr}^{6+}\right)$ in the environment restrict its widespread application under RoHS (restriction of hazardous substances) compliance. Thus, $\mathrm{Ni}-\mathrm{W}$ alloy seems to be a proper alternative to the hard chromium coating [6]. In addition to its admirable characteristics, different types of ceramic particles can be incorporated in $\mathrm{Ni}-\mathrm{W}$ alloys through electrochemical methods, such as $\mathrm{SiC}, \mathrm{SiO}_{2}, \mathrm{Si}_{3} \mathrm{~N}_{4}$, $\mathrm{Al}_{2} \mathrm{O}_{3}, \mathrm{TiO}_{2}, \mathrm{Cr}_{2} \mathrm{O}_{3}$, diamond, WC, CNT, and $\mathrm{MoS}_{2}$ [7-10].

$\mathrm{SiC}$ nanoparticles are among the most widely utilized second-phase reinforcements in the composite system to produce hard and wear-resistant coatings. The widespread interest in $\mathrm{SiC}$ is attributed to its excellent thermal stability, oxidation 
resistance, high hardness, wear resistance, commercially available, and cost-effectiveness [7]. The final properties of the metal matrix composite system depend particularly on the properties of both reinforced particles and the matrix phase. Thus, the outstanding functional properties of composite coatings can be achieved by the synergic effect of the particles and the matrix. The incorporation of the particles leads to the change in alloy microstructures [11] due to the interaction between particles and the electrocrystallization process [12]. Therefore, the inclusion of inert particles with the growing metal alloy plays an essential role in improving the properties of the nanocomposite coating.

Usually, the electrodeposition is carried out by using different techniques such as passing direct current (DC), pulsed current (PC), and pulse reverse current (PRC). In the direct current technique, the current flow is continuous during the electrodeposition process. Application of direct current to produce Ni-W alloy coating has revealed some defects, such as increased residual tensile stress resulting in crack formation, in the coatings [13]. Besides, the use of pulse reverse current in the Ni-W alloy induces residual stress, crack formation, and reduced $\mathrm{W}$ content, which is considered as the major drawback of this technique. On the other hand, pulse current is a powerful technique to control microstructure and chemical composition, mainly due to its ability to enhance the current distribution and mass transfer process. Thus, the use of the pulse current enhances the properties of the coating by improving the microstructure and refined grains of the alloy matrix [13]. As a result, the coating becomes harder, uniform, and possesses admirable mechanical properties. Moreover, a large number of investigations have highlighted that the increased codeposition of ceramics particles in the metal alloy is attributed to the use of pulse current. For example, Kumar et al. [14] demonstrated that the use of pulse current produced uniform surface, improved corrosion resistance, and higher microhardness of $\mathrm{Ni}-\mathrm{W}-\mathrm{TiO}_{2}$ composite coating than the coating obtained from the direct current technique.

A number of investigations have been performed on the electrodeposition of the Ni-W-SiC composite system. However, there are no studies available with a detailed investigation of the effect of direct and pulse current on the scratch resistance properties of the $\mathrm{Ni}-\mathrm{W}-\mathrm{SiC}$ composite coating to our best knowledge. Hence, in this study, the effectiveness of DC and PC techniques on the surface, microstructures, microhardness, and scratch resistance properties of $\mathrm{Ni}-\mathrm{W}$ and $\mathrm{Ni}-\mathrm{W}-\mathrm{SiC}$ composite coatings has been systematically investigated.
Table 1 Experimental bath formulation

\begin{tabular}{lll}
\hline Composition & Concentration & Purpose \\
\hline $\mathrm{NiSO}_{4} \cdot 6 \mathrm{H}_{2} \mathrm{O}(\mathrm{mol})$ & 0.075 & Ni source \\
$\mathrm{Na}_{2} \mathrm{WO}_{4} \cdot 2 \mathrm{H}_{2} \mathrm{O}(\mathrm{mol})$ & 0.112 & W source \\
$\mathrm{Na}_{3} \mathrm{C}_{6} \mathrm{H}_{5} \mathrm{O}_{7} \cdot \mathrm{H}_{2} \mathrm{O}(\mathrm{mol})$ & 0.187 & Complexing agent \\
$\mathrm{NH}_{4} \mathrm{Cl}(\mathrm{mol})$ & 0.5 & Buffer \\
$\mathrm{NaBr}(\mathrm{mol})$ & 0.6 & Conductivity \\
$\mathrm{SDS}(\mathrm{g} / \mathrm{L})$ & 0.3 & Surfactant \\
$\mathrm{SiC}$ particles $(\mathrm{g} / \mathrm{L})$ & 0,20 & Composite phase \\
\hline
\end{tabular}

Table 2 Electrodeposition conditions

\begin{tabular}{llllll}
\hline $\begin{array}{l}\text { Tempera- } \\
\text { ture }\left({ }^{\circ} \mathrm{C}\right)\end{array}$ & $\begin{array}{l}\text { Electro- } \\
\text { deposition } \\
\text { time }(\mathrm{min})\end{array}$ & $\begin{array}{l}\text { Current } \\
\text { density } \\
\left(\mathrm{mA} / \mathrm{cm}^{2}\right)\end{array}$ & $\begin{array}{l}\text { Stirring/ } \\
\text { agitation } \\
(\mathrm{rpm})\end{array}$ & Anode & Cathode \\
\hline 65 & 60 & 80 & 180 & Graphite & Copper \\
\hline
\end{tabular}

\section{Experimental}

\subsection{Material}

Nickel sulfate $\left(\mathrm{NiSO}_{4} \cdot 6 \mathrm{H}_{2} \mathrm{O}, 99 \%\right.$ purity), sodium tungstate $\left(\mathrm{Na}_{2} \mathrm{WO}_{4} \cdot 2 \mathrm{H}_{2} \mathrm{O}, 99 \%\right.$ purity), and sodium bromide ( $\mathrm{NaBr}, 99 \%$ purity) were obtained from Sigma-Aldrich Company. Similarly, trisodium citrate $\left(\mathrm{Na}_{3} \mathrm{C}_{6} \mathrm{H}_{5} \mathrm{O}_{7} \cdot \mathrm{H}_{2} \mathrm{O}\right.$, $98 \%$ purity) and ammonium chloride $\left(\mathrm{NH}_{4} \mathrm{Cl}, 98.5 \%\right.$ purity) were received from DUKSAN pure chemicals Co., Ltd. Silicon carbide ( $\beta$-SiC, ultra-fine) was purchased from IBIDEN Co., Ltd. All of the chemicals were utilized as received without any further purification in this study.

\subsection{Preparation of $\mathrm{Ni}-\mathrm{W}$ Alloys and $\mathrm{Ni}-\mathrm{W}-\mathrm{SiC}$ Composite Coatings}

The composition and concentration of the electroplating bath utilized in the experiment are summarized in Table 1 . Similarly, conditions for the electrodeposition are listed in Table 2. The $\mathrm{SiC}$ nanoparticles $(20 \mathrm{~g} / \mathrm{L}$, average particle size $270 \mathrm{~nm}$ ) were added to the electroplating bath. The suspension containing $\mathrm{SiC}$ particles was ultrasonically agitated for $30 \mathrm{~min}$ prior to the electrodeposition process to avoid agglomeration. A graphite rod was used as an anode and a polished copper substrate as the cathode. The cathode was masked, leaving $1.5 \mathrm{~cm} \times 2.0 \mathrm{~cm}$ exposed surface area for deposition. Then, both electrodes were placed in the electrolyte solution $(250 \mathrm{~mL})$. The distance between anode and cathode was fixed to be approximately $3 \mathrm{~cm}$, adjusting parallel to each other. During the 
electrodeposition process, the temperature of the electrolyte solution was maintained to $65{ }^{\circ} \mathrm{C}$ and the solution was mechanically stirred at $180 \mathrm{rpm}$ to perform agitation. The current density was maintained to $80 \mathrm{~mA} / \mathrm{cm}^{2}$, pulse frequency of $100 \mathrm{~Hz}$, and duty cycle of $50 \%$ for $60 \mathrm{~min}$ to achieve the desired thickness of the coating. After electrodeposition, the samples were cleaned ultrasonically in the distilled water for $3 \mathrm{~min}$ to remove loosely adsorbed $\mathrm{SiC}$ nanoparticles.

\subsection{Characterization}

All synthesized samples were examined using equipment fitted with modern technology. The surface morphologies of fabricated samples were observed by scanning electron microscopy (SEM, Nanoeye). X-ray diffraction (XRD, Rigaku DMAX 2200, Japan) and energy-dispersive X-ray spectrometer (EDS) were used to examine the microstructures and the element compositions of the samples, respectively. The surface roughness tester (Mitutoyo Surftest SV-600, Japan) was used to measure the average roughness $\left(R_{\mathrm{a}}\right)$, root mean square $\left(R_{\mathrm{q}}\right)$, and maximum roughness depth $\left(R_{\max }\right)$ of the coatings. The microhardness of the coatings was determined by using Vickers microhardness tester (Buehler Ltd., USA) under $5 \mathrm{~N}$ loads for $10 \mathrm{~s}$. The average values were taken from ten different places on the surface of composite coatings. In addition, the measurements were executed with enough distance between indentations to ensure avoiding any possibility of damage during the test.

Scratch test was carried out by utilizing the sophisticated model scratch tester (CSEM Revetest) with a $200-\mu \mathrm{m}$ diamond stylus. Progressive load mode of the scratch test was performed on the surface of the coating with a loading range from 0 to $50 \mathrm{~N}$. During the scratch measurement, an acoustic emission signal and the coefficient of friction were recorded simultaneously to determine the scratch-resistant behavior of the coatings. Moreover, SEM was used to observe and collect the images of the scratched surfaces.

\section{Results and Discussion}

\subsection{Microstructures, Surface Morphologies, and Phase Compositions}

Figure 1a shows the XRD patterns of $\mathrm{Ni}-\mathrm{W}$ and $\mathrm{Ni}-\mathrm{W}-\mathrm{SiC}$ composite coatings, where four peaks at $2 \theta$ equal to $44.01^{\circ}$, $50.26^{\circ}, 74.38^{\circ}$, and $89.86^{\circ}$ are associated with (111), (200), (220), and (311) planes, respectively. All peaks of the composite coatings correspond to the face-centered cubic (FCC) structure. As shown in Fig. 1b, the magnification of (111) peak discloses a slightly peak shift toward a lower $2 \theta$ angle for Ni-W PC samples as compared to Ni-W DC. The reason could be attributed to an increment of $\mathrm{W}$ amount. The substitution by a larger $\mathrm{W}$ atom (radius: $1.39 \AA$ ) in the lattice of smaller Ni atom (radius: $1.24 \AA$ ) might have resulted in compressive stress in the coating [15]. No additional peaks of the amorphous phase or the precipitated $\mathrm{NiWO}_{4}$ phase appeared, which is in good agreement with the previous investigation [16].

The most critical factors influencing the crystal structure of the $\mathrm{Ni}-\mathrm{W}-\mathrm{SiC}$ coating are considered to be the content of $\mathrm{W}$ and $\mathrm{SiC}$ [7]. As shown in Fig. 1b, embedded $\mathrm{SiC}$ in $\mathrm{Ni}-\mathrm{W}$ alloy matrix of both DC and PC coatings shifted the (111) peak to the lower angle. The peaks associated with the reinforced $\mathrm{SiC}$ particles were not observed in XRD. The possible reason could be the low amount of $\mathrm{SiC}$ nanoparticles that fell behind the XRD detection limit [16]. The nickel-tungsten alloy has revealed a face-centered cubic phase dominated by $\mathrm{Ni}-\mathrm{W}$ solid solution.
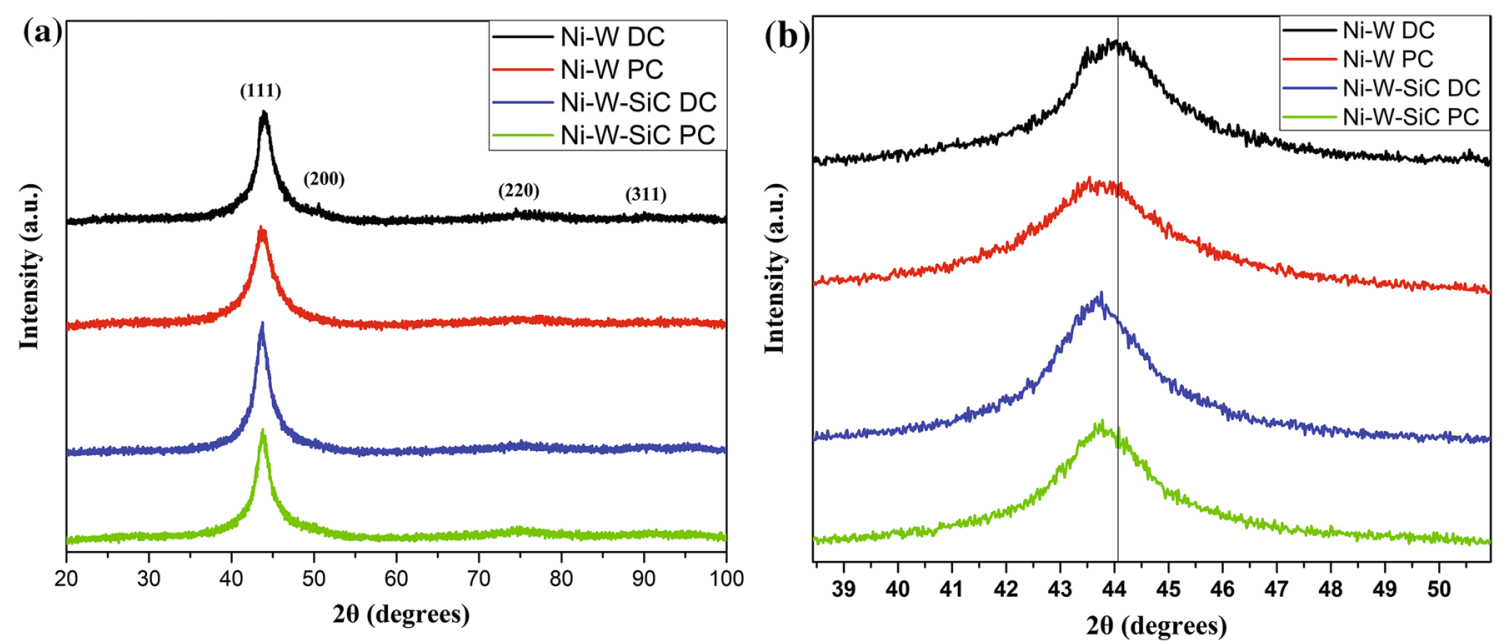

Fig. 1 XRD patterns of a Ni-W and Ni-W-SiC coatings, $\mathbf{b}$ corresponding higher magnification of (111) peak 
Determination of matrix grain size is one of the essential aspects to evaluate the mechanical properties of a coating such as microhardness and scratch resistance. Hence, the $\mathrm{Ni}-\mathrm{W}$ matrix grain size was calculated with respect to the broadening of the (111) main peak using Scherrer's equation [17]. The calculated matrix grain size and the lattice strain are listed in Table 3. Change in the type of current in electroplating affected the grain size accordingly. Pulse current refined the grain size of $\mathrm{Ni}-\mathrm{W}$ matrix to $8.5 \mathrm{~nm}$ as compared to direct current $(12 \mathrm{~nm})$. The possible reason is ascribed to the hindrance of the grain growth toward increased nucleation in the alloy coating. Furthermore, incorporation of SiC in the alloy showed a slight change in grain size equal to $9.1 \mathrm{~nm}$ and $9.2 \mathrm{~nm}$ for PC and DC techniques, respectively. Consequently, lattice strain is also increased with the reduction in grain size, as illustrated in Table 3.

Table 3 Grain size and lattice strain of $\mathrm{Ni}-\mathrm{W}$ and $\mathrm{Ni}-\mathrm{W}-\mathrm{SiC}$ composite coatings

\begin{tabular}{lll}
\hline Samples & Grain size $(\mathrm{nm})$ & Lattice strain $(\%)$ \\
\hline Ni-W DC & 12 & 0.0876 \\
Ni-W PC & 8.5 & 0.1185 \\
Ni-W-SiC DC & 9.2 & 0.1111 \\
Ni-W-SiC PC & 9.1 & 0.1124 \\
\hline
\end{tabular}
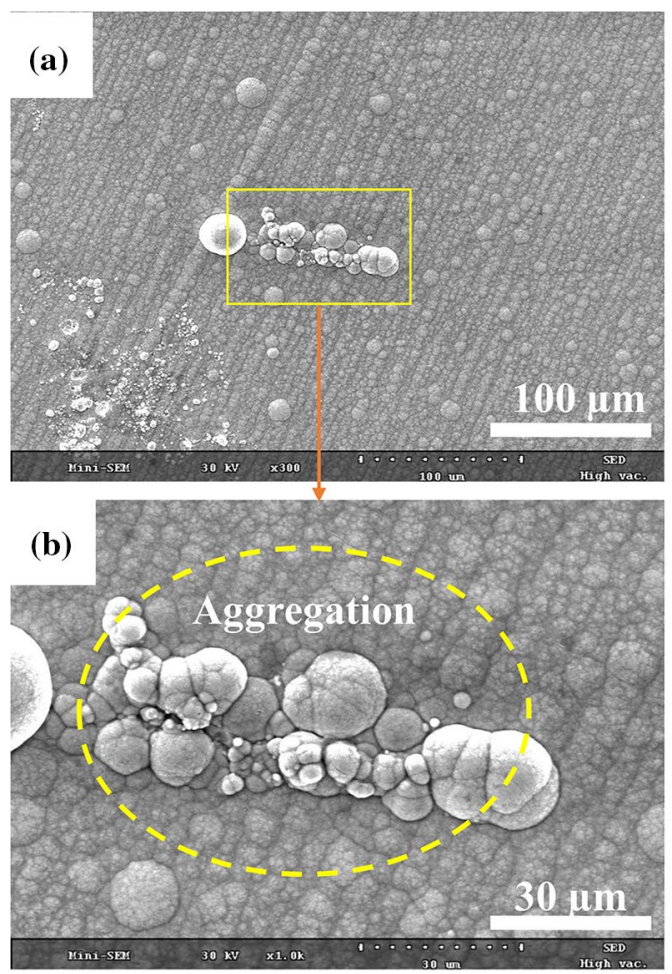

SEM images of the surface morphologies of Ni-W and $\mathrm{Ni}-\mathrm{W}-\mathrm{SiC}$ coatings along with their higher-magnification images are shown in Figs. 2 and 3, respectively. Similarly, the surface roughness values $\left(R_{\mathrm{a}}, R_{\mathrm{q}}, R_{\max }\right)$ of the electrodeposited $\mathrm{Ni}-\mathrm{W}$ and $\mathrm{Ni}-\mathrm{W}-\mathrm{SiC}$ composite coatings are presented in Table 4. As illustrated in Fig. 2a, b, the surface morphology of Ni-W DC coating discloses a large nodular size, non-uniform distribution, and an aggregated matrix component. On the other hand, the Ni-W PC coatings (Fig. 2c, d) show a smoother surface with a flat area that might be due to the restriction of crystalline bulk growth (nodules cluster) during the electrodeposition process. The surface roughness values are also well aligned with the observation. The average surface roughness $\left(R_{\mathrm{a}}\right)$ of $\mathrm{Ni}-\mathrm{W}$ PC coating $(0.224 \mu \mathrm{m})$ is lower than that of $\mathrm{Ni}-\mathrm{W}$ DC coating $(0.358 \mu \mathrm{m})$.

However, the addition of a certain amount of $\mathrm{SiC}$ nanoparticles into the plating bath in DC condition increased the nodule size, as shown in Fig. 3a, b, which was also confirmed by the increased surface roughness of the Ni-W-SiC DC coating $(1.170 \mu \mathrm{m})$ as compared to $\mathrm{Ni}-\mathrm{W} \mathrm{DC}(0.358 \mu \mathrm{m})$ coating. The result is in agreement with studies $[18,19]$, as the embedded submicron-sized particles in the alloy lead to an increase in the surface roughness. On the contrary, with the use of pulse current, the roughness of the surface reduced to $0.736 \mu \mathrm{m}$ in the $\mathrm{Ni}-\mathrm{W}-\mathrm{SiC}$ PC sample. The outcome is also reflected in the surface morphology images, as
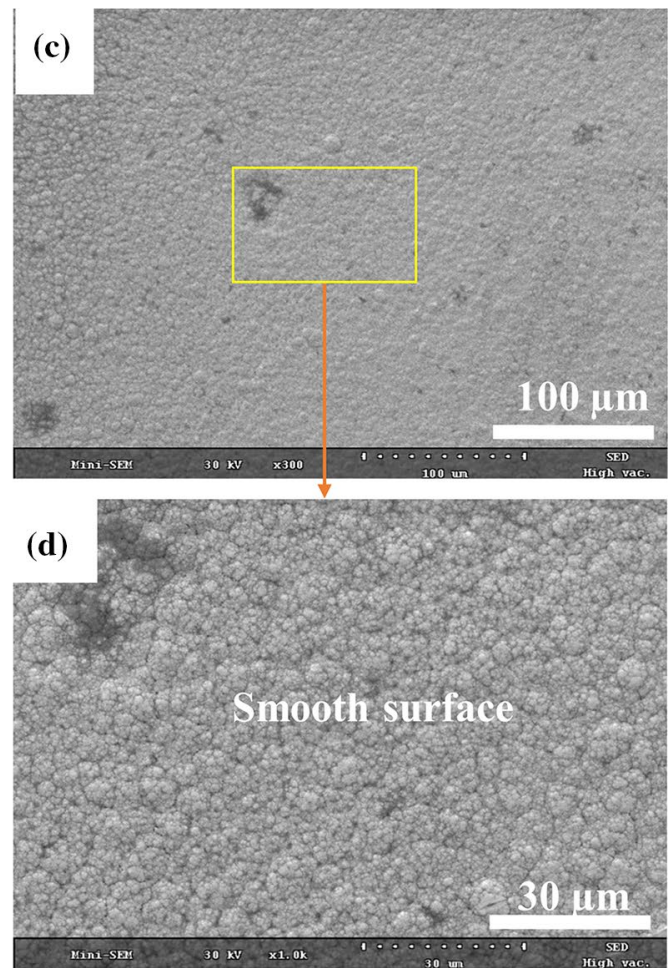

Fig. 2 SEM images of the surface morphologies of a Ni-W DC, $\mathbf{c}$ Ni-W PC coatings; $\mathbf{b}, \mathbf{d}$ their corresponding higher-magnification images 

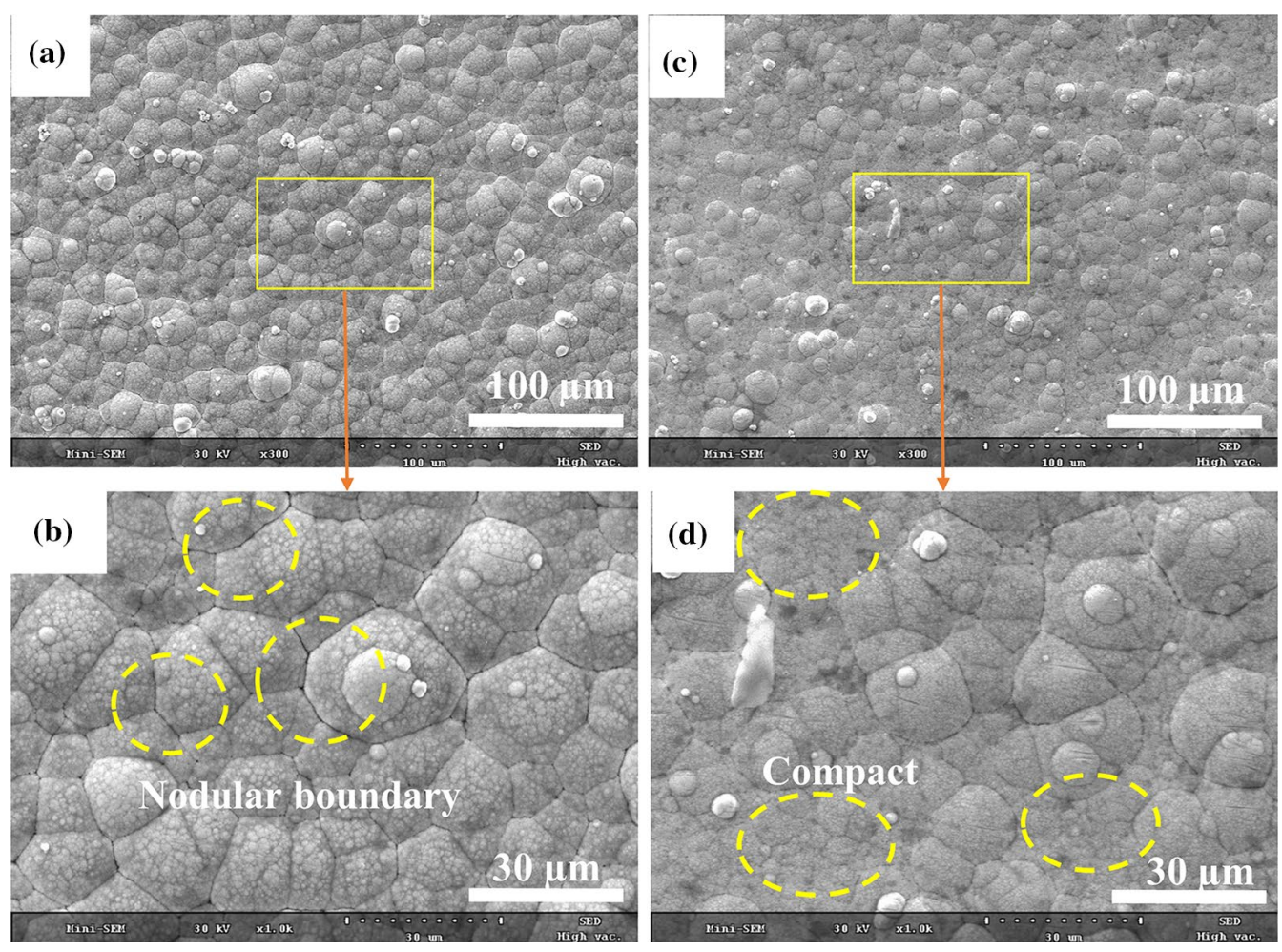

Fig. 3 SEM images of the surface morphologies of a Ni-W-SiC DC, $\mathbf{c}$ Ni-W-SiC PC coatings; $\mathbf{b}, \mathbf{d}$ their corresponding higher-magnification images

Table 4 Surface roughness profiles of $\mathrm{Ni}-\mathrm{W}$ and $\mathrm{Ni}-\mathrm{W}-\mathrm{SiC}$ composite coatings

\begin{tabular}{llll}
\hline Samples & $R_{\mathrm{a}}(\mu \mathrm{m})$ & $R_{\mathrm{q}}(\mu \mathrm{m})$ & $R_{\max }(\mu \mathrm{m})$ \\
\hline Ni-W DC & 0.358 & 0.704 & 2.375 \\
Ni-W PC & 0.224 & 0.344 & 1.677 \\
Ni-W-SiC DC & 1.170 & 1.496 & 7.519 \\
Ni-W-SiC PC & 0.735 & 0.920 & 4.324 \\
\hline
\end{tabular}

shown in Fig. 3c, d. A similar observation was reported by Kumar et al. [14] where the surface roughness of the coating decreased in PC condition. As shown in Fig. 2d, although the pulse current enhanced the smoothness of the surface, some minor coating defects such as miniature pore-like appearance are still existed, which might be due to the evolution of $\mathrm{H}_{2}$. In the same respect, the problem of $\mathrm{H}_{2}$ embrittlement is one of the disadvantages in electrodeposited coatings [13]. On the other hand, the incorporation of $\mathrm{SiC}$ in the $\mathrm{Ni}-\mathrm{W}$ alloy reduced those defects on the surface (Fig. 3d). As can be observed from SEM, the embedded $\mathrm{SiC}$ nanoparticles in $\mathrm{Ni}-\mathrm{W}$ alloy altered the morphology and roughness of the surface. Hence, the Ni-W and $\mathrm{Ni}-\mathrm{W}-\mathrm{SiC}$ composite coatings obtained from PC condition demonstrated a smooth surface and smaller spherical shape of nodules as compared to the coatings achieved from the DC condition.
The element compositions of the $\mathrm{Ni}-\mathrm{W}$ and $\mathrm{Ni}-\mathrm{W}-\mathrm{SiC}$ coatings were analyzed by using the EDS technique. As shown in Fig. 4, the contents of $\mathrm{Ni}, \mathrm{W}, \mathrm{Si}$, and $\mathrm{C}$ have been changed depending on the type of current utilized during electrodeposition. According to Fig. 4a, b, Ni-W DC coating possesses lesser content of $\mathrm{W}(26.34 \mathrm{wt} \%)$ as compared to Ni-W PC (31.05 wt\%), respectively. The increment of $\mathrm{W}$ content corresponds to a finer Ni-W alloy [13]. As a sequence, Vamsi et al. [20] mentioned that the higher content of $\mathrm{W}$ in $\mathrm{Ni}-\mathrm{W}$ coatings decreased the surface roughness, which is also observed in our findings on surface profiles of the coatings.

On the other hand, incorporation of $\mathrm{SiC}$ into the $\mathrm{Ni}-\mathrm{W}$ alloy matrix reduced the amount of $\mathrm{Ni}$ and $\mathrm{W}$. The decrease in $\mathrm{Ni}$ and $\mathrm{W}$ contents during the codeposition of ceramic particles can be explained in terms of Faraday's efficiency [18]. Similarly, the contents of W, Si, and C slightly increased in Ni-W-SiC PC coating (Fig. 4d) as compared to Ni-W-SiC DC coating (Fig. 4c). The increased codeposition of $\mathrm{SiC}$ nanoparticles into the $\mathrm{Ni}-\mathrm{W}$ alloy under pulsed current condition might be ascribed to the increased transportation rate of the particles and cations toward the cathode surface. The transportation rate, which is also determined by current density, leads to improving the adsorption of the particles on the growing film at the cathode surface [7]. In the same respect, Allahyarzadeh et al. [13] reported that the 

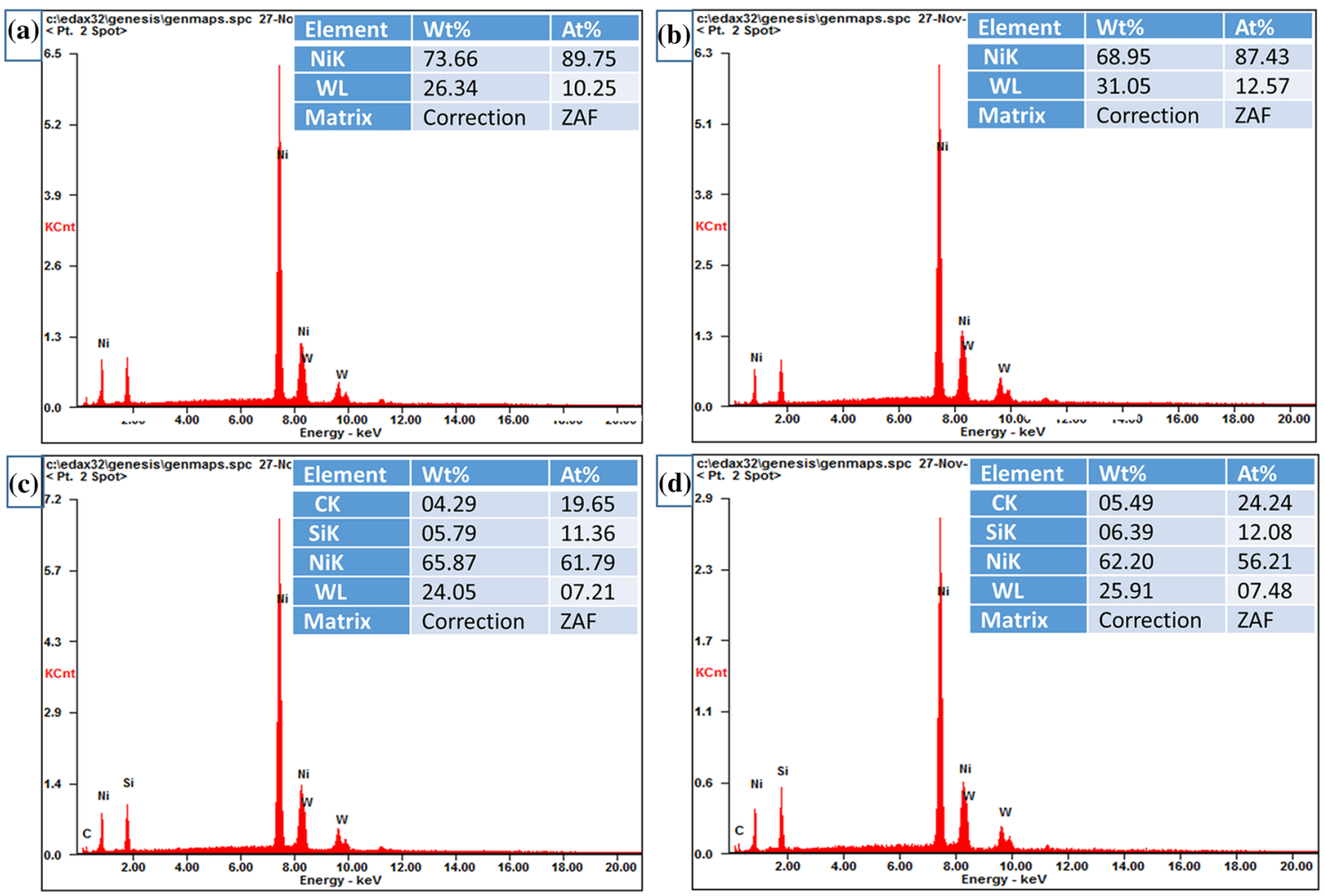

Fig. 4 EDS spectra of: a Ni-W DC, b Ni-W PC, $\mathbf{c}$ Ni-W-SiC DC, $\mathbf{d}$ Ni-W-SiC PC coatings

enhanced current distribution and mass transfer processes were influenced by the pulsed current. Thus, the element composition is affected by the incorporation of the SiC particles and the type of current used.

In order to confirm the coating thickness and distribution of $\mathrm{SiC}$ particles in the Ni-W alloy, SEM images of the cross section of all coatings were taken as shown in Fig. 5. The cross-sectional images of $\mathrm{Ni}-\mathrm{W}$ coatings prepared under DC and PC conditions, as shown in Fig. 5a, b, respectively, reveal almost similar coating thickness $(\sim 39 \mu \mathrm{m})$. On the other hand, an average thickness of $\mathrm{Ni}-\mathrm{W}-\mathrm{SiC}$ coatings is approximately $\sim 49 \mu \mathrm{m}$ (Fig. $5 \mathrm{c}, \mathrm{d}$ ). Coating cross sections of the $\mathrm{Ni}-\mathrm{W}-\mathrm{SiC}$ composite show a distinct difference in the distribution patterns of the embedded SiC particles. The homogeneous distribution of $\mathrm{SiC}$ particles is observed in the Ni-W-SiC PC coating, as shown in Fig. 5d.

\subsection{Microhardness}

In order to get a clear indentation by avoiding the roughness effect of the surface, Vickers microhardness was measured on the polished surface of the samples. As shown in Fig. 6, Ni-W alloy coatings display noticeable variations in microhardness values. The average Vickers microhardness of $\mathrm{Ni}-\mathrm{W}$ PC coating was measured to be $528 \mathrm{HV}$, nearly twofold than the $\mathrm{Ni}-\mathrm{W}$ DC coating
(308 HV). The significant improvement in microhardness of Ni-W PC coating can be illustrated in terms of grain refinement as well as increased lattice strain, as shown in Table 3. Direct current electrodeposited Ni-W alloy showed larger grain as well as weaker lattice strain, which eventually increased the indentation impression of the applied load. In addition, the variation in microhardness values might also be due to the variation of $\mathrm{W}$ contents in the deposits. Higher content of $\mathrm{W}$ in $\mathrm{Ni}-\mathrm{W}$ alloy leads to increasing microhardness of the coating [16].

Among all samples, $\mathrm{Ni}-\mathrm{W}-\mathrm{SiC} \mathrm{PC}$ coating has shown the highest microhardness. The possible reasons could be the embedded $\mathrm{SiC}$ in association with the change in chemical composition, load-bearing capacity due to the dispersed $\mathrm{SiC}$ particles, and the strength in microstructure [7]. Liu et al. [21] reported that the codeposition of micron-sized diamond in the Ni-Mo nanocrystalline matrix (grain size $<10 \mathrm{~nm}$ ) improved the Vickers microhardness of the composite coatings. According to their investigation, the primary reason to improve the microhardness of the composite coating was ascribed to the occurrence of matrix-diamond interfaces that possess excellent stability and limited mobility as compared to the matrix grain boundaries. Likewise, in the present work, the distribution of submicron-sized SiC particles in $\mathrm{Ni}-\mathrm{W}$ matrix probably created more matrix/SiC interfaces in the composite coating that led to higher microhardness. 


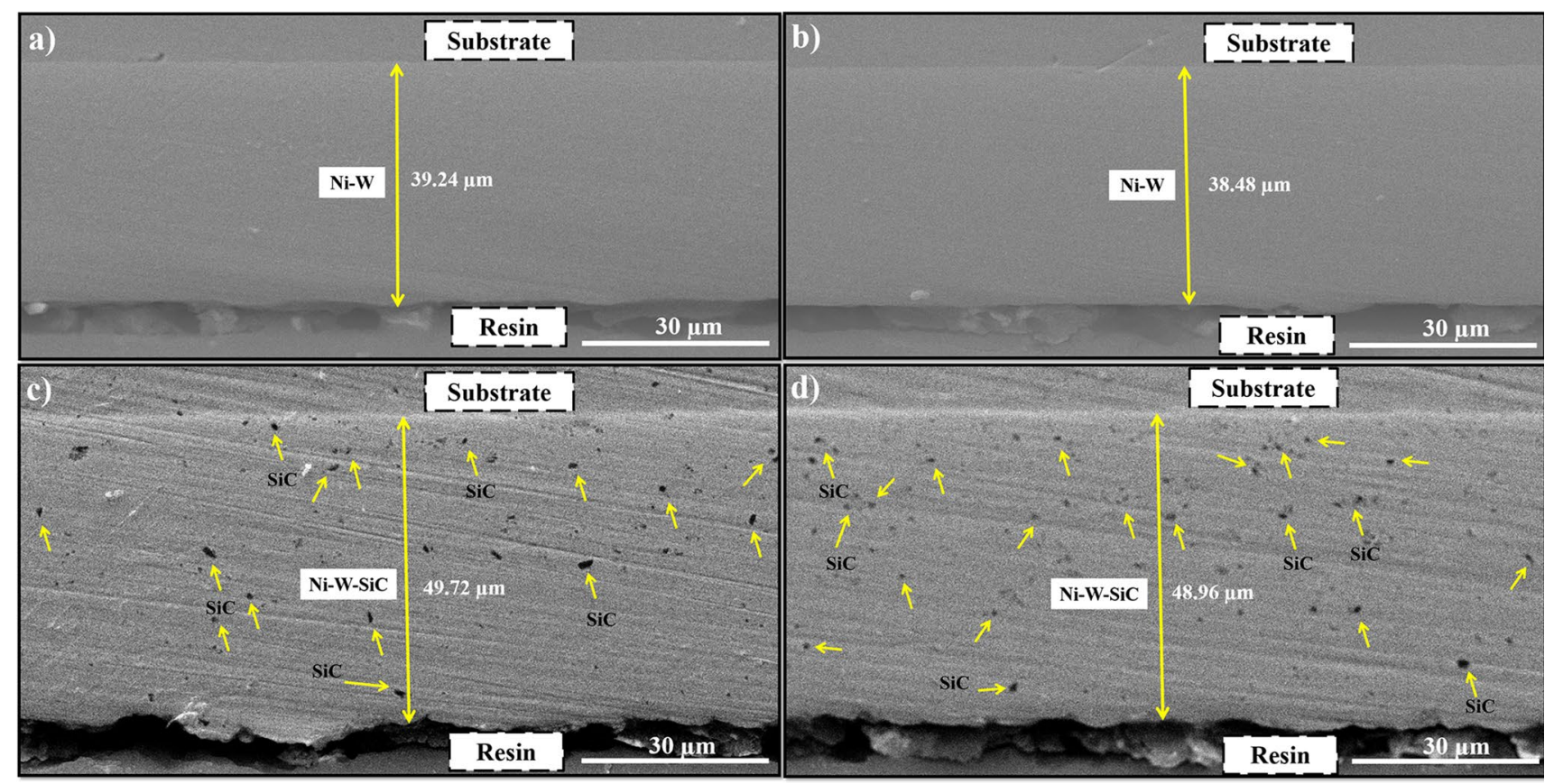

Fig. 5 SEM images of the cross sections of a Ni-W DC, b Ni-W PC, $\mathbf{c}$ Ni-W-SiC DC, $\mathbf{d}$ Ni-W-SiC PC coatings

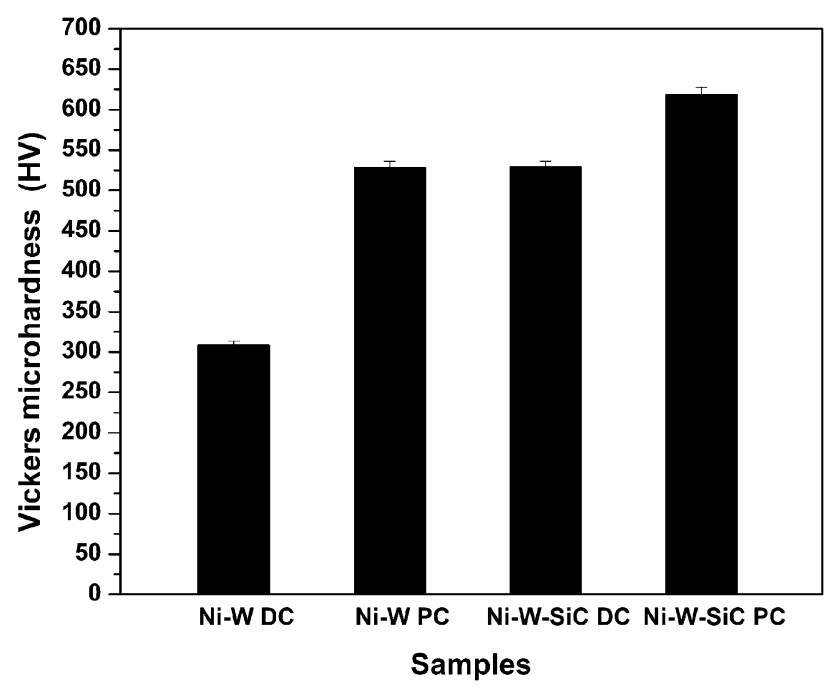

Fig. 6 Variation of Vickers microhardness of the coatings

The microhardness of Ni-W-SiC PC coating ( $619 \mathrm{HV})$ is higher in comparison with the Ni-W-SiC DC coating $(\sim 529 \mathrm{HV})$. The outcome might be attributed to the content of codeposited $\mathrm{SiC}, \mathrm{W}$ content, and grain refinement. A difference of $1.8 \mathrm{wt} \%$ is found in the weight percentage of $\mathrm{SiC}$ in $\mathrm{Ni}-\mathrm{W}-\mathrm{SiC} \mathrm{PC}(11.88 \mathrm{wt} \%)$ and $\mathrm{Ni}-\mathrm{W}-\mathrm{SiC}$ DC (10.08 wt \%) coatings. Moreover, the content of $\mathrm{W}$ in $\mathrm{Ni}-\mathrm{W}-\mathrm{SiC}$ PC (25.91 wt\%) is higher than Ni-W-SiC DC (24.05 wt\%), as revealed by EDS analysis (Fig. 4c, d). The results reveal that the increased content of $\mathrm{SiC}$ and $\mathrm{W}$ in the deposit led to improving the Vickers microhardness. Furthermore, the experimental results revealed a slight reduction in the grain size in $\mathrm{Ni}-\mathrm{W}-\mathrm{SiC} \mathrm{PC}$ coating as compared to $\mathrm{Ni}-\mathrm{W}-\mathrm{SiC}$ DC. In addition, it has been reported that pulse current enhances microhardness, reduces porosity, and leads to a compact structure by refining grain size [14]. Hence, our findings support the idea that pulse current improves the hardness in either $\mathrm{Ni}-\mathrm{W}$ alloy or $\mathrm{Ni}-\mathrm{W}-\mathrm{SiC}$ composite coating, ultimately leading to promoting the mechanical properties of the coating.

\subsection{Scratch Test}

It is well known that the Ni-W alloy coating is relatively hard and brittle [18]. Thus, for the identification of the integral adhesion of this brittle coating, differential loads were utilized during the scratch test, as mentioned in previous studies [22, 23]. Moreover, two characteristics loads, i.e., cohesive load $\left(L_{\mathrm{C}}\right)$ and adhesive load $\left(L_{\mathrm{A}}\right)$, are commonly used to determine scratch resistance behavior, which are further confirmed with an optical and electron microscopes. As the loading is progressive type, the appearance of the first crack in the coating at the given load is characterized as a cohesive load, while the minimum load that causes coating detachment is ascribed as the adhesive load. Both the loads are recognized with the aid of an acoustic emission signals obtained during the measurement [22].

The variation in a coefficient of friction and acoustic emission signals obtained during the scratch test of different 


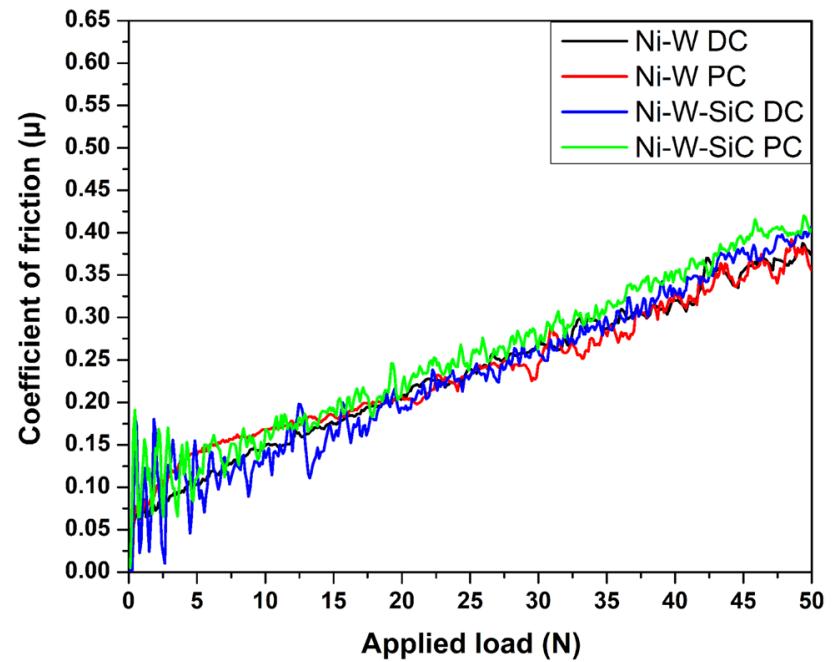

Fig. 7 Coefficient of friction obtained during the scratch test of Ni-W and $\mathrm{Ni}-\mathrm{W}-\mathrm{SiC}$ coatings

samples is shown in Fig. 7. Different samples possessed their characteristic frictional behaviors corresponding to the progressive loading. According to Fig. 7, Ni-W alloy and $\mathrm{Ni}-\mathrm{W}-\mathrm{SiC}$ composite coatings have displayed nearly similar nature and average values of the coefficient of friction. The similarity in the frictional behavior of all samples could be associated with the microstructure and brittleness of $\mathrm{Ni}-\mathrm{W}$ alloys by virtue of their intrinsic nature. For example, similar results have been reported by Gyawali et al. [18], where a significant difference in the frictional behaviors was not observed between $\mathrm{Ni}-\mathrm{W}$ alloy and $\mathrm{Ni}-\mathrm{W}-\mathrm{TiB}_{2}$ composite coatings.

Similarly, the cohesive load can be determined with the aid of the acoustic emission signal obtained during the scratch test. Figure 8 shows the acoustic emission signals of different samples with respect to increasing loads in the range $0-50 \mathrm{~N}$. In addition, the acoustic emission (AE) peaks were raised initially at different applied loads. Among all samples, Ni-W PC coating shows the first acoustic emission peak activated from $28 \mathrm{~N}$, while in other samples, the peak started to appear as early from $2 \mathrm{~N}$. The reason could be associated with the smooth surface of Ni-W PC coating as compared to other samples.

The adhesive load is characterized by the intense and sharp rise in acoustic emission signals. As shown in Fig. 8, the intense acoustic emission signals were obtained for $\mathrm{Ni}-\mathrm{W}-\mathrm{SiC}$ samples, especially in a lower load range $(10-25 \mathrm{~N})$. The sharp rise in acoustic emissions at lower loads could be a result of compression of the hard and brittle coating into the soft substrate (copper) due to the action of moving stylus [22]. On the other hand, Ni-W alloy coatings have exhibited a gradual increase in acoustic emissions at higher loading range, i.e., 30-45 N. As reported

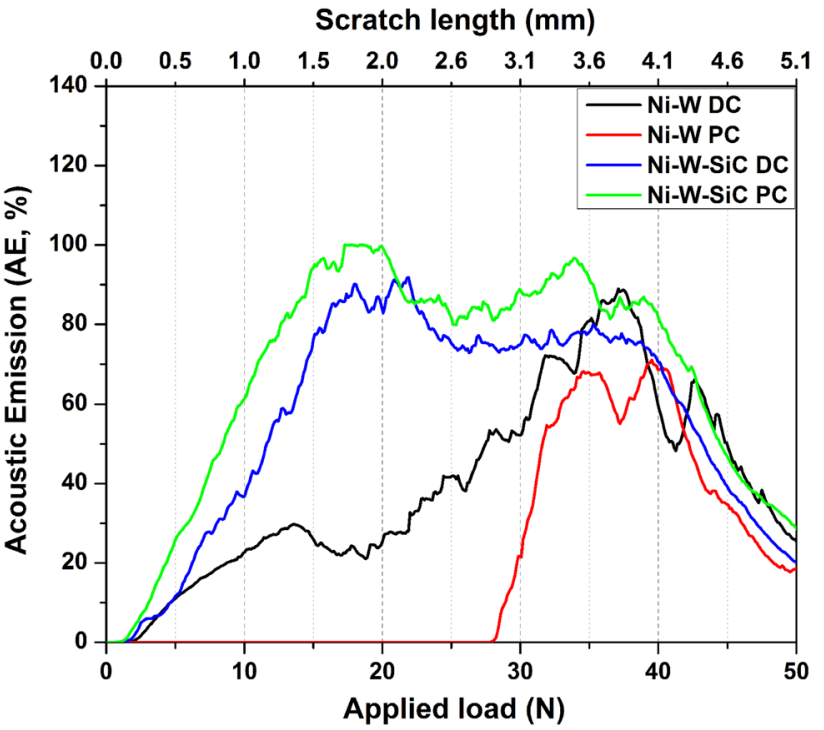

Fig. 8 Acoustic emission signals recorded during the scratch test of $\mathrm{Ni}-\mathrm{W}$ and $\mathrm{Ni}-\mathrm{W}-\mathrm{SiC}$ coatings

by Papachristors et al. [22], the increment in acoustic emission with respect to higher loads could be the indication of the propagation of cracks during the progressive load in the scratch test. Despite the differences in the appearance of the acoustic emission peaks, there is an agreement that all samples show similar behavior toward higher loads in progressive loading. Thus, emission signals that appeared in the range between 0 and $50 \mathrm{~N}$ of applied loads have shown variations in peak positions and intensities for different samples with significant slope at the end of this range.

Another way to determine the adhesive strength of the coating is the appearance of intense acoustic emission signals resulted from the coating detachment. However, the intense acoustic emission signal is not primarily mean to a coating detachment. A series of cracks networking might also result in the intense acoustic emission signal. In addition, the strength of coating and substrate, the thickness of the coating, fracture toughness, etc., might influence the sudden rise in the AE signal [22]. Hence, a sudden rise of AE may not be exclusively referred to a coating detachment. Therefore, the determination of cohesive strength is a complicated parameter due to several factors involved during the scratch test.

Figure 9 displays the collated and higher-magnification SEM images of the scratched surfaces of the coatings. According to Fig. 9a, b, Ni-W alloys show a relatively higher number of micro-cracks and their propagation indicating brittleness of the coating. However, noticeable differences are observed in the first appearance of the crack between Ni-W DC and Ni-W PC coatings. Microcracks appear earlier in Ni-W DC. In addition, Ni-W PC presents less number of cracks, which is consistent with 

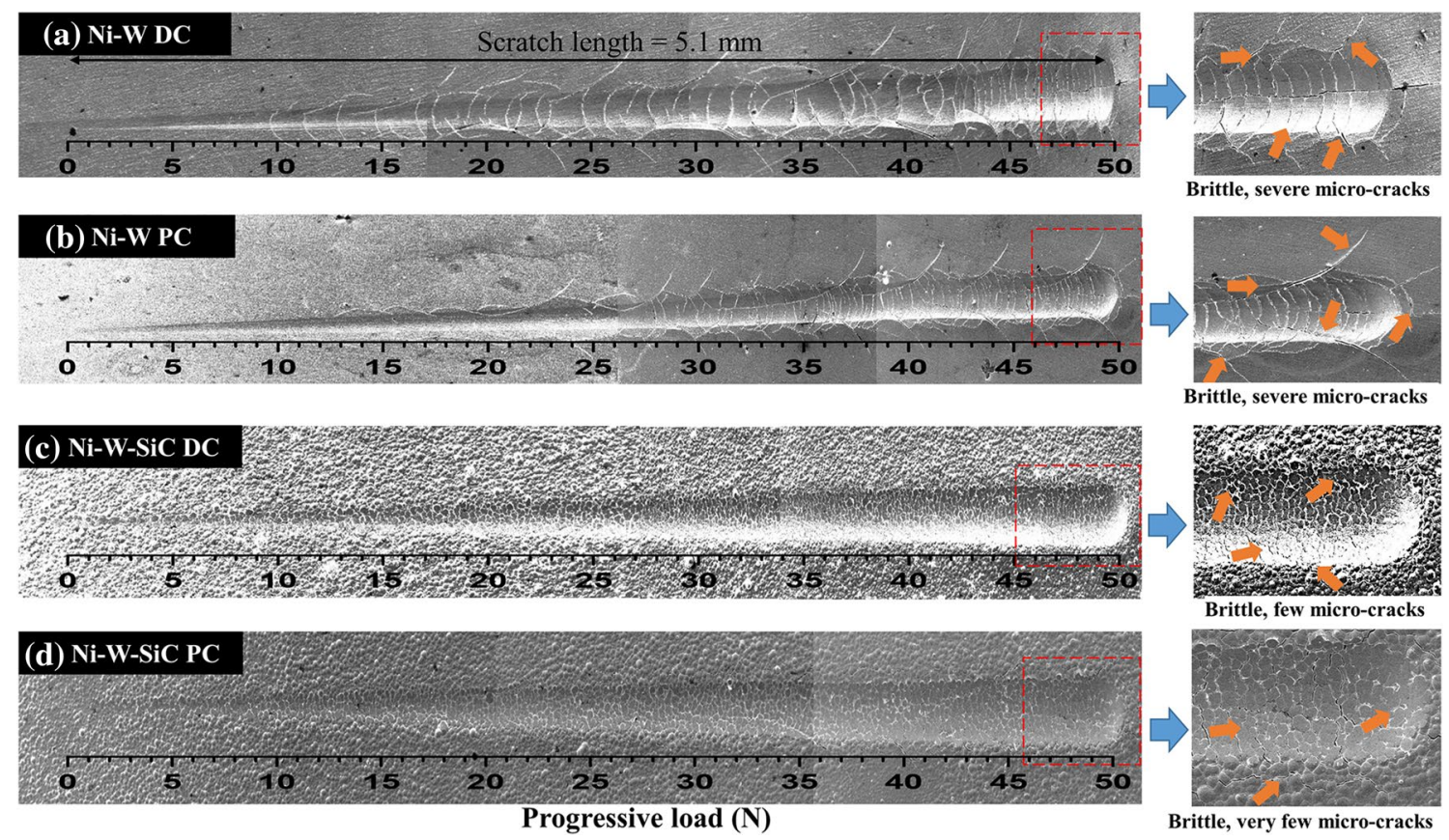

Fig. 9 Collated SEM images of the worn surfaces of a Ni-W DC, b Ni-W PC, $\mathbf{c}$ Ni-W-SiC DC, $\mathbf{d}$ Ni-W-SiC PC coatings after scratch test

the acoustic emission signals (Fig. 8). Consequently, an enhancement is recognized on the mechanical properties of Ni-W alloy coating by using pulse current. Apart from this improvement, the primary reason for cracks formation in all coatings is ascribed to the brittle nature of the $\mathrm{Ni}-\mathrm{W}$ alloy matrix.

On the other hand, micro-cracks are significantly reduced in $\mathrm{Ni}-\mathrm{W}-\mathrm{SiC}$ composite coatings (Fig. 9c, d) as compared to $\mathrm{Ni}-\mathrm{W}$ alloys. The incorporation of $\mathrm{SiC}$ particles into the Ni-W alloy matrix clearly indicates the reduced number of cracks formation. It is noted that embedded $\mathrm{SiC}$, as reinforcement, in the $\mathrm{Ni}-\mathrm{W}$ alloy led to changing microstructure; thus, the composite coating maintained more scratch resistance in the progressive loading. Furthermore, the embedded $\mathrm{SiC}$ particles into $\mathrm{Ni}-\mathrm{W}$ alloy properly acted as a barrier to crack propagation, resulting in the improvement in scratch resistance. Despite the significant reduction in micro-cracks in $\mathrm{Ni}-\mathrm{W}-\mathrm{SiC}$ coatings, the appearance of micro-cracks and their propagations nearly perpendicular to the moving stylus in the coating was not completely disappeared. As aforementioned, the brittle nature of $\mathrm{Ni}-\mathrm{W}$ alloy could be the main cause. Hence, embedded $\mathrm{SiC}$ in $\mathrm{Ni}-\mathrm{W}$ alloy under direct and pulse technique enhanced the scratch resistance properties as compared to Ni-W alloy. Furthermore, the significant reduction in cracks might also be ascribed to the increment in hardness in terms of the altered microstructure, elemental compositions, and grain size of the Ni-W-SiC composite coatings.

\section{Conclusion}

In summary, $\mathrm{Ni}-\mathrm{W}$ alloy and $\mathrm{Ni}-\mathrm{W}-\mathrm{SiC}$ composite coatings were electrodeposited with the aid of direct current (DC) and pulse current (PC) techniques. Application of pulse current enhanced the codeposition of $\mathrm{SiC}$ particles, reduced the matrix grain size, and produced compact, smooth, and homogeneous surface morphology, leading to higher microhardness in respective $\mathrm{Ni}-\mathrm{W}$ alloy or Ni-W-SiC coatings. Similarly, scratch-resistant studies revealed a considerable improvement in scratch-resistant behavior of the Ni-W alloy and the composite coating prepared under PC condition. Furthermore, micro-cracks formation and their propagations were significantly reduced by the embedded $\mathrm{SiC}$ particles in $\mathrm{Ni}-\mathrm{W}$ alloys. The application of pulse current not only improved the surface- and microstructure-related properties but also enhanced Vickers microhardness and scratch resistance properties of the coatings.

Acknowledgements This work was financially supported by the $\mathrm{PhD}$ full funding scholarship from the National Institute for International Education (NIIED), Republic of Korea.

\section{References}

[1] C.G. Fink, P.J.D. Prince, Trans. Am. Electrochem. Soc. 54, 315 (1928) 
[2] G. Gyawali, B. Joshi, K. Tripathi, S.W. Lee, J. Mater. Eng. Perform. 26, 4462 (2017)

[3] E. Beltowska-lehman, P. Indyka, A. Bigos, M.J. Szczerba, M. Kot, Mater. Des. 80, 1 (2015)

[4] A. Genc, M. Lutfi Ovecoglu, M. Baydogan, S. Turan, Mater. Des. 42, 495 (2012)

[5] P. Indyka, E. Beltowska-lehman, L. Tarkowski, A. Bigos, E. García-lecina, J. Alloys Compd. 590, 75 (2014)

[6] N.P. Wasekar, S.M. Latha, M. Ramakrishna, D.S. Rao, G. Sundararajan, Mater. Des. 112, 140 (2016)

[7] B. Li, W. Zhang, W. Zhang, Y. Huan, J. Alloys Compd. 702, 38 (2017)

[8] Y. Yao, S. Yao, L. Zhang, H. Wang, Mater. Lett. 61, 67 (2007)

[9] L. Tian, J. Xu, C. Qiang, Appl. Surf. Sci. 257, 4689 (2011)

[10] N. Spyrellis, E.A. Pavlatou, S. Spanou, A. Zoikis-karathanasis, Trans. Nonferrous Met. Soc. China 19, 800 (2009)

[11] A.F. Zimmerman, D.G. Clark, K.T. Aust, U. Erb, Mater. Lett. 52, 85 (2002)

[12] P. Nowak, R.P. Socha, M. Kaisheva, J. Fransaer, J.P. Celis, Z. Stoinov, J. Appl. Electrochem. 30, 429 (2000)

[13] M.H. Allahyarzadeh, M. Aliofkhazraei, A.R. Rezvanian, V. Torabinejad, A.R. Sabour Rouhaghdam, Surf. Coat. Technol. 307, 978 (2016)
[14] K.A. Kumar, G.P. Kalaignan, V.S. Muralidharan, Ceram. Int. 39, $2827(2013)$

[15] O.S.A. Rahman, N.P. Wasekar, G. Sundararajan, A.K. Keshri, Mater. Charact. 116, 1 (2016)

[16] G. Gyawali, B. Joshi, K. Tripathi, S.W. Lee, Ceram. Int. 42, 3497 (2016)

[17] G. Gyawali, S.H. Cho, D.J. Woo, S.W. Lee, Trans. Inst. Met. Finish. 90, 274 (2012)

[18] G. Gyawali, K. Tripathi, B. Joshi, S.W. Lee, J. Alloys Compd. 721, 757 (2017)

[19] M.F. Cardinal, P.A. Castro, J. Baxi, H. Liang, F.J. Williams, Surf. Coat. Technol. 204, 85 (2009)

[20] M.V.N. Vamsi, N.P. Wasekar, G. Sundararajan, Surf. Coat. Technol. 319, 403 (2017)

[21] J.H. Liu, Z.L. Pei, W.B. Shi, Y.D. Liu, J. Gong, C. Sun, Surf. Coat. Technol. 385, 125451 (2020)

[22] V.D. Papachristos, C.N. Panagopoulos, L.W. Christoffersen, A. Markaki, Thin Solid Films 396, 174 (2001)

[23] F.C. Chang, M. Levy, R. Huie, M. Kane, P. Buckley, T.Z. Kattamis, G.R. Lakshminarayan, Surf. Coat. Technol. 49, 87 (1991) 